\title{
Ultrasound-B scan: an indispensable tool for diagnosing ocular cysticercosis
}

\author{
Amar Pujari, Rohan Chawla, Rashmi Singh, Aditi Mehta
}

Department of Ophthalmology, Dr. Rajendra Prasad Centre for Ophthalmic Sciences, All India Institute of Medical Sciences, New Delhi, India

\section{Correspondence to \\ Dr Amar Pujari,}

dramarpujari@gmail.com

Accepted 9 April 2017

\section{DESCRIPTION}

Ocular cysticercosis is still an important parasitic infection in low/middle-income countries, as its diagnosis requires meticulous ocular examination followed by skilful usage of point-focused ultrasound imaging for confirmation of the diagnosis. A 26-year-old woman presented with a history of recurrent redness in the left eye, which was not responsive to topical medications. Clinical examination showed congestion in the inferior conjunctiva with the rest of the anterior and posterior segments being within normal limits. Subsequent ultrasound examination of the extraocular muscle showed a large cyst inferior to the rectus muscle with a high amplitude localised spike corresponding to scolex (figure 1A). In a second scenario, a middle-aged female patient presented with painless diminution of vision in the left eye; because of the hazy media, a posterior segment ultrasonography was performed which showed a well-defined cystic cavity in the mid-vitreous with a high amplitude echo suggesting a cysticercosis. (figure $1 \mathrm{~B}$ ) In a third case, an ultrasonographic examination for suspected subretinal cysticercosis revealed the presence of scolex behind the retina (figure $2 \mathrm{~A}$ ). In a fourth case, a patient presented with painless diminution of vision; because of the hazy media, an ultrasonography examination of the posterior segment was done which showed a retinal detachment with a scolex and cyst anterior to it (figure 2B).

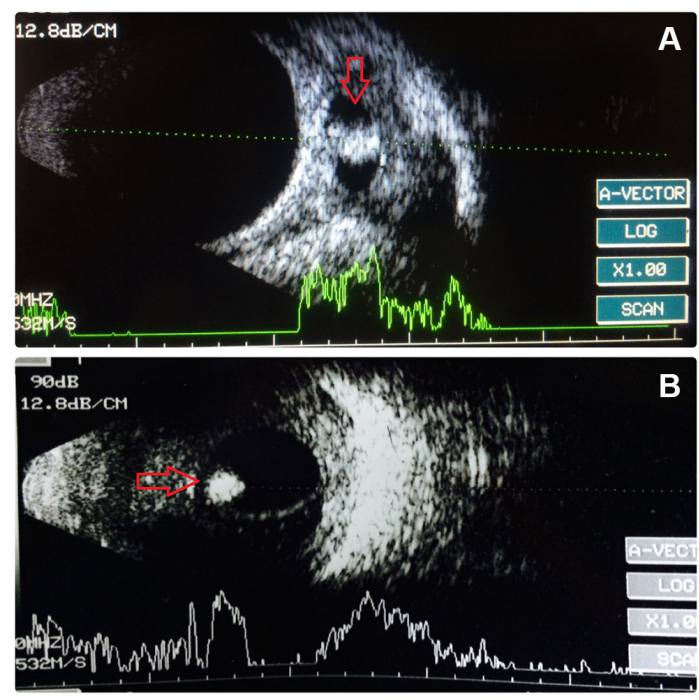

Figure 1 (A) Large inferior rectus muscle cyst with high amplitude echo corresponding to the scolex (arrow). (B) Cyst within the mid-vitreous with a scolex inside (arrow).
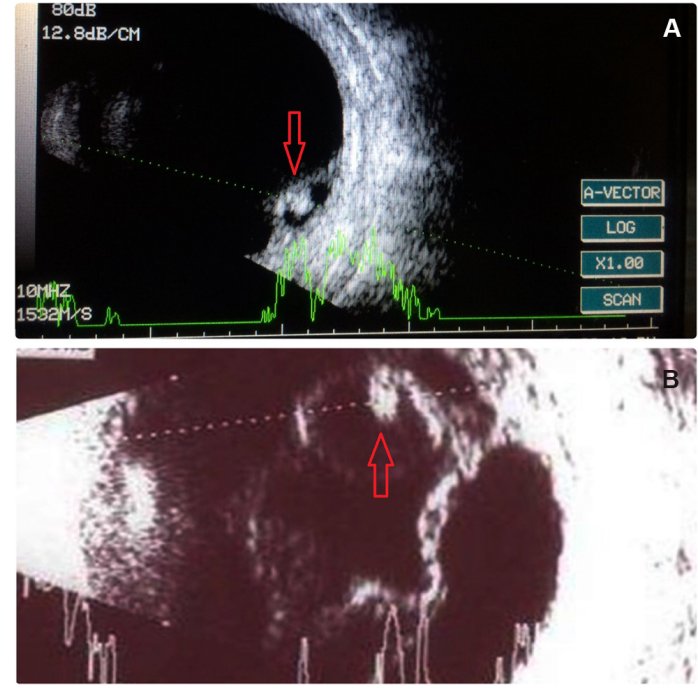

Figure 2 (A) Small localised retinal elevation with a dot-like echo corresponding to scolex (arrow). (B) Total retinal detachment along with vitreous exudates and a cyst containing scolex (arrow) anterior to the retina.

The diagnosis of ocular and extraocular muscle cysticercosis is a clinical challenge in many situations. Studies comparing ultrasonography and CT for diagnosing these conditions have shown that both are equally effective. ${ }^{1}$ But ultrasound is preferred for initial evaluation because it is a cheap, portable and easily available tool. In cases of hazy media, ultrasound plays an important role in identifying the location of the cyst in the vitreous subretinal space along with associated retinal detachment. Similarly, in extraocular cases with recurrent bulbar conjunctival congestion with or without extraocular motility restriction in endemic regions, performing ultrasound to look for extraocular muscle

Learning points

- Ultrasound is an initial, economical and preferred imaging modality for the diagnosis of ocular cysticercosis.

- In cases of opaque ocular media, ultrasound is the best-suited tool for the identification of posterior segment cyst with scolex.

- Ultrasound imaging can be easily repeated by a single observer at regular intervals during follow-up until the complete regression of the cyst. 
cysticercosis is a logical initial step to find a typically enlarged muscle with scolex within it. Another advantage of ultrasonography is its repeatability without any risk of radiation exposure; in cases of extraocular muscle cysticercosis, it is repeated after every 2 weeks until the disappearance of scolex (usually around 2-4 weeks) and progressive reduction until complete disappearance of the cyst (usually around 6-8 weeks). CT and MRI are the other imaging modalities that are equally effective; however, because of the risk of radiation exposure and its cost CT has its own limitations. Similarly, MRI does not pose radiation risks but costs more and its availability is a concern. ${ }^{2}$ Patients with intraocular cysticercosis underwent vitrectomy with cyst removal and the patient with extraocular muscle cysticercosis received albendazole $(15 \mathrm{mg} / \mathrm{kg})$ along with prednisolone $(1 \mathrm{mg} / \mathrm{kg})$ for 4 weeks.
Contributors AP, RC and RS have performed the ultrasound for different cases and carried out critical assessment. AP, RC, RS and AM have analysed the literature for the educational value of this important topic and wrote the report together.

Competing interests None declared.

Patient consent Obtained.

Provenance and peer review Not commissioned; externally peer reviewed.

(C) BMJ Publishing Group Ltd (unless otherwise stated in the text of the article) 2017. All rights reserved. No commercial use is permitted unless otherwise expressly granted.

\section{REFERENCES}

1 Sekhar GC, Honavar SG. Myocysticercosis: experience with imaging and therapy. Ophthalmology 1999;106:2336-40.

2 Shi D, Li S, Guo Y, et al. [A diagnostic analysis of imaging in ocular cysticercosis]. Zhonghua Yan Ke Za Zhi Chin J Ophthalmol 2000;36:56-8.

Copyright 2017 BMJ Publishing Group. All rights reserved. For permission to reuse any of this content visit http://group.bmj.com/group/rights-licensing/permissions.

BMJ Case Report Fellows may re-use this article for personal use and teaching without any further permission.

Become a Fellow of BMJ Case Reports today and you can:

- Submit as many cases as you like

- Enjoy fast sympathetic peer review and rapid publication of accepted articles

- Access all the published articles

- Re-use any of the published material for personal use and teaching without further permission

For information on Institutional Fellowships contact consortiasales@bmjgroup.com

Visit casereports.bmj.com for more articles like this and to become a Fellow 